\title{
Correction to: Diagnostic significance of SPACE for PCIS
}

\author{
Qurratulain Hyder ${ }^{1} \cdot$ Haider $\mathrm{Khh}^{2}$
}

Published online: 19 March 2018

(c) Japanese Society of Gastroenterology 2018

\section{Correction to: Clinical Journal of Gastroenterology https://doi.org/10.1007/s12328-018-0836-6}

In the original publication of the article, the first sentence of the listed point 2, in page 1 should read as "Advanced pancreatic cancer is diagnosed by pancreatic juice cytology in $<50 \%$ of cases."

The original article can be found online at https://doi.org/10.1007/ s12328-018-0836-6.

Qurratulain Hyder

qhyder2194@hotmail.co.uk

1 Gastroenterology Clinic (IBP), Pakistan Institute of Medical Sciences, G-8/3, Islamabad, Pakistan

2 Department of Basic Sciences, SRC, Qassim, Kingdom of Saudi Arabia 